\title{
Compensação e Incentivo à Proteção Ambiental: o caso do ICMS Ecológico em Minas Gerais
}

\author{
Luciany Lima Fernandes ${ }^{1}$ \\ Alexandre Bragança Coelho ${ }^{2}$ \\ Elaine Aparecida Fernandes ${ }^{3}$ \\ João Eustáquio de Lima ${ }^{4}$
}

\begin{abstract}
Resumo: O ICMS Ecológico, criado em 1991 no Paraná, surgiu da reivindicação dos municípios que sentiam que suas economias eram prejudicadas pelas restrições de uso do solo, originadas por serem mananciais de abastecimento para municípios vizinhos ou por integrarem Unidades de Conservação. Dessa forma, o poder público estadual sentiu a necessidade de reformular os critérios de distribuição do ICMS, favorecendo estes municípios com recursos adicionais. Em Minas Gerais, o ICMS Ecológico foi criado em 1995, através da Lei Robin Hood. No sentido de verificar o impacto desse instrumento, esse artigo teve como objetivo analisá-lo nas suas funções de compensação e incentivo aos municípios mineiros. Nesse sentido, foram calculados os índices consolidados de produção e de preservação para todos os municípios mineiros, e utilizou-se um modelo de dados em painel para verificar qual a relação entre a área protegida e o valor do ICMS Ecológico recebido através do subcritério Unidades de Conservação. Os resultados obtidos mostram que esse instrumento compensa a maior parte dos municípios, mas vem perdendo sua importância nos últimos anos. Quanto ao incentivo, o ICMS Ecológico realmente incentiva a preservação e a conservação do meio ambiente, pois há uma relação direta entre o montante recebido e o crescimento de áreas protegidas nos municípios mineiros.
\end{abstract}

Palavras-chave: ICMS Ecológico, Minas Gerais, Modelo de Dados em Painel e Unidades de Conservação.

1 Mestre em Economia Aplicada pela Universidade Federal de Viçosa. E-mail: lucianyufv@yahoo.com.br

2 Professor da Universidade Federal de Viçosa. E-mail: acoelho@ufv.br

3 Professora da Universidade Federal de Viçosa. E-mail: eafernandes@ufv.br

4 Professor titular da Universidade Federal de Viçosa. E-mail: jelima@ufv.br 


\begin{abstract}
The Ecological ICMS was first used to distribute a share of the ICMS revenue in the Paraná state in 1991. This pioneer experience originated from counties' claims which argued that their economies were harmed by land use restrictions, mainly because they were watershed protection areas or their territory was part of a conservation unit. Responding to these claims, the state government changed the ICMS allocation criteria, favoring those counties with added funds. In the Minas Gerais state, the Ecological ICMS was implemented in 1995 with the "Robin Hood Law". The objective of this study was to evaluate the Ecological ICMS in Minas Gerais as an instrument for compensation and incentive. Production and preservation indexes were calculated for all Minas Gerais counties and a panel data model was used to verify the relationship between the amount of Ecological ICMS received and the protected area in each county. Results showed the creation of a conservation unit would compensate most of Minas Gerais counties because of the Ecological ICMS, although the attractiveness of the conservation option has been declining systematically over the years. Regarding the incentive effect of the Ecological ICMS, results showed that the Ecological ICMS really compensates and incentives Minas Gerais counties to preserve the environment because there is a direct relationship between the amount received from the Ecological ICMS and the growth of protected areas in Minas Gerais counties.
\end{abstract}

Key-words: Ecological ICMS, Minas Gerais, Panel Data Model, Conservation Units.

Classificação JEL: Q28; C23.

\title{
1. Introdução
}

O Imposto sobre Circulação de Mercadorias e Serviços (ICMS) é um imposto estadual sobre o valor adicionado de bens e serviços. A Constituição de 1988 determinou que $25 \%$ das receitas do ICMS deveriam ser transferidas dos estados para os municípios que os compõem. A Constituição também estipulou que no mínimo 75\% desta receita transferida deveria ser distribuída de acordo com o valor adicionado gerado em cada município ${ }^{5}$, e o restante seria distribuído de acordo com critérios de alocação que cada estado achasse mais conveniente ao seu caso específico. Os indicadores usados normalmente eram baseados no tamanho da população, área do município e produção primária local.

Em 1991, o critério ecológico passou a ser utilizado para distribuir parte destes recursos no estado do Paraná. Esta experiência pioneira originou-se da reivindicação dos municípios que sentiam que suas economias eram

5 Para cada município, o valor adicionado mede a produção econômica do município, traduzida pela diferença entre o somatório das notas fiscais de venda e o somatório das notas fiscais de compra. 
prejudicadas pelas restrições de uso do solo, originadas por serem mananciais de abastecimento para municípios vizinhos ou por integrarem Unidades de Conservação. Dessa forma, o poder público estadual sentiu a necessidade de reformular os critérios de distribuição do ICMS, favorecendo estes municípios com recursos adicionais. Apesar de o ICMS Ecológico nascer sob a égide da compensação, sua característica mais importante é constituir-se num mecanismo de incentivo à conservação ambiental, representando uma promissora alternativa na composição dos instrumentos de política pública para a conservação ambiental no Brasil (LOUREIRO, 2002).

Após a experiência do Paraná, os estados de São Paulo (1993), Minas Gerais (1995), Rondônia (1996), Amapá (1996), Rio Grande do Sul (1997), Mato Grosso (2000), Mato Grosso do Sul (2000), Pernambuco (2000), Tocantins (2002) e Rio de Janeiro (2007) também implantaram o ICMS Ecológico, com pequenas modificações entre eles. A Tabela 1 mostra os estados com legislações já aprovadas, a distribuição percentual e os critérios atuais de distribuição dos recursos do ICMS Ecológico dos estados brasileiros.

Em Minas Gerais, o ICMS Ecológico foi criado através da Lei Complementar Estadual n. 12.040/95, chamada de Lei Robin Hood . O modelo mineiro, além do critério ambiental, inclui outros como: patrimônio cultural, educação, produção de alimentos, número de habitantes por município, 50 municípios mais populosos, receita própria municipal, saúde e área geográfica (MINAS GERAIS, 1995).

Tabela 1. Estados brasileiros que possuem ICMS Ecológico implementado e os percentuais para o repasse de recursos financeiros, 2008.

\begin{tabular}{lcccc}
\hline & \multicolumn{4}{c}{ Critérios (\%) } \\
\cline { 2 - 5 } \multicolumn{1}{c}{ Estado } & $\begin{array}{c}\text { Unidades de } \\
\text { Conservação, terras } \\
\text { indígenas e outras } \\
\text { áreas especialmente } \\
\text { protegidas }\end{array}$ & $\begin{array}{c}\text { Coletae } \\
\text { destinação final } \\
\text { de lixo, esgoto }\end{array}$ & $\begin{array}{c}\text { Controle de } \\
\text { a indas, combate } \\
\text { conservação manejo } \\
\text { do solo }\end{array}$ & $\begin{array}{c}\text { Mananciais de } \\
\text { abastecimento } \\
\text { público de água }\end{array}$ \\
\hline Paraná & 2,5 & - & - & 2,5 \\
São Paulo & 0,5 & - & - & - \\
Minas Gerais & 0,5 & 0,5 & - & - \\
Rondônia & 5,0 & - & - & - \\
Amapá & 1,4 & - & - & - \\
Rio Grande do Sul & 7,0 & - & - & - \\
Mato Grosso do Sul & 5,0 & - & - & - \\
Pernambuco & 1,0 & 5,0 & - & - \\
Mato Grosso & 5,0 & 2,5 & & - \\
Tocantins & 3,5 & 3,5 & 6,0 & 0,8 \\
Rio de Janeiro & 1,1 & 0,6 & - & - \\
\hline
\end{tabular}

Fonte: Paraná (1991); São Paulo (1993); Minas Gerais (1995); Rondônia (1996); Amapá (1996); Rio Grande do Sul (1997); Mato Grosso (2000); Mato Grosso do Sul (2000); Pernambuco (2000); Tocantins (2002); Rio de Janeiro (2007). 
Entre os critérios para repartição do ICMS aos municípios mineiros, o critério ambiental (ICMS Ecológico) representa 1\% dos recursos, dividido em dois subcritérios. O primeiro refere-se às Unidades de Conservação. A lei destina $0,5 \%$ aos municípios que abrigam espaços especialmente protegidos. $\mathrm{O}$ sistema engloba áreas públicas ou privadas das três esferas de governo, que são cadastradas junto à Secretaria de Estado de Meio Ambiente e Desenvolvimento Sustentável, após a avaliação técnica do Instituto Estadual de Florestas. O segundo subcritério refere-se ao sistema de tratamento ou disposição final de lixo urbano e tratamento de esgoto sanitário, destinando 0,5\% do total dos recursos a serem repassados aos municípios que possuem sistema de tratamento ou disposição final de lixo urbano que atenda pelo menos $70 \%$ da população, ou sistema de tratamento de esgoto sanitário que atenda pelo menos $50 \%$ da população ${ }^{6}$ (NUNES, 2003).

A Figura 1 apresenta o total de ICMS Ecológico repassado aos municípios mineiros e o número de municípios que recebem o ICMS Ecológico, no período de 1997 a 2007. Pode-se observar que o valor repassado aos municípios aumentou consideravelmente neste período. Em 2007, foram repassados aos municípios $\mathrm{R} \$ 41,04$ milhões referentes ao critério ecológico, aumento de aproximadamente $68,29 \%$ em relação a 1997 . Com relação ao número de municípios que recebem o ICMS Ecológico, observa-se que, no período analisado, o número cresceu consideravelmente. Em 2007, havia 366 municípios mineiros, dos 853 que compõem o estado, que recebiam o ICMS Ecológico, alta de aproximadamente 198\% em relação a 1997.

O ICMS Ecológico foi introduzido através da diminuição do peso do critério de valor adicionado ${ }^{7}$. Ao mudar os critérios de distribuição, muitos municípios com Unidades de Conservação aumentaram sua receita. Entretanto, éimportante observar que muitos municípios perderam receita pelo fato de o critério de valor adicionado ter perdido importância ${ }^{8}$. Além disso, para municípios considerados pequenos ou de pouca expressão econômica, o repasse ecológico representou mais de $20 \%$ do repasse total feito pelo estado, sendo uma fonte importante de recursos (GRIEG-GRAN, 2000).

6 Em 2000, havia 23 e 212 municípios que recebiam o ICMS Ecológico através dos critérios saneamento e Unidades de Conservação, respectivamente. Em 2007, havia 104 e 310. Para mais detalhes, ver Fernandes (2008).

7 Ver anexo A.

8 Grieg-Gran (2000), ao analisar os dados de Minas Gerais em 1998, concluiu que 86 municípios com Unidades de Conservação foram beneficiados com aumento de receita pela introdução do ICMS Ecológico, enquanto 38 municípios perderam receita pela diminuição do critério de valor adicionado. 
Figura 1. Total de ICMS Ecológico repassado aos municípios mineiros, em R\$. Número de municípios mineiros que recebem o ICMS Ecológico, período 1997 a 2007.

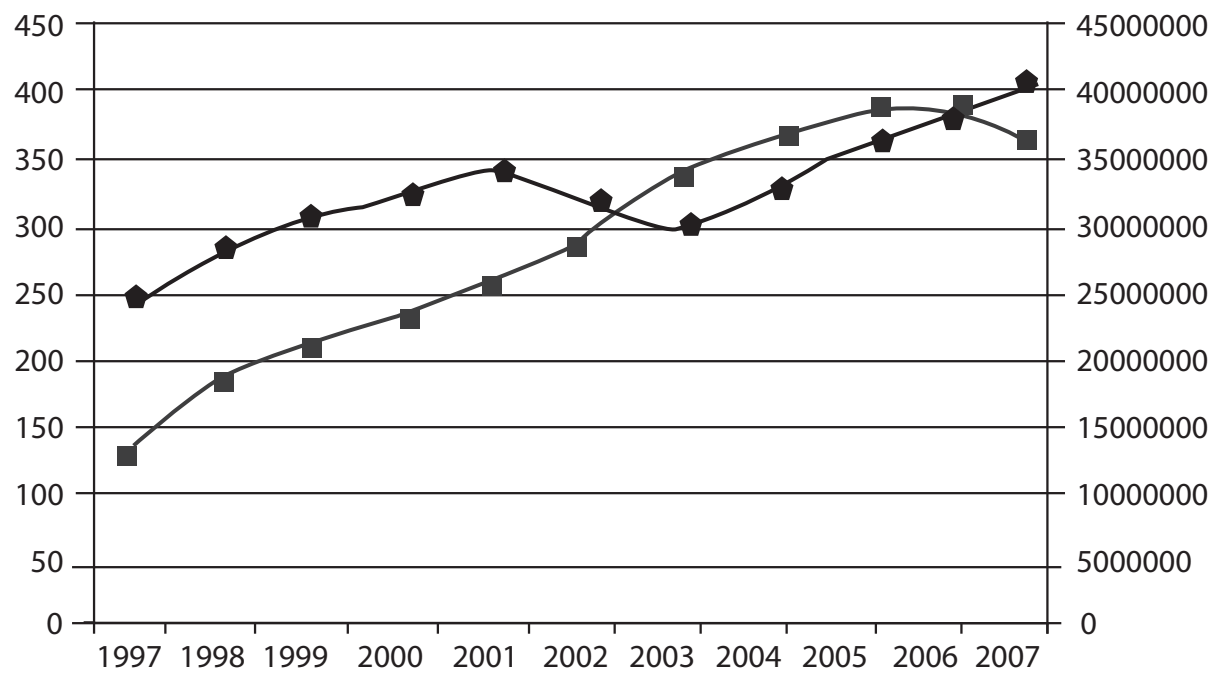

$\longrightarrow$ Número de municípios $ـ \longrightarrow$ Total de ICMS Ecológico

Fonte: Fundação João Pinheiro.

Em relação a outros estudos já realizados sobre o ICMS Ecológico, Botelho et al. (2007) analisaram o ICMS Ecológico como um instrumento de política ambiental em Minas Gerais. Veiga Neto (2000) estudou o impacto do ICMS Ecológico em dois municípios de Minas Gerais, Marliéria e Araponga. Como Grieg-Gran (2000), este estudo procurou analisar o ICMS Ecológico como um mecanismo de compensação e incentivo. Porém, ao contrário desse estudo, a análise foi realizada, no período de 1997 a 2007, para todos os municípios mineiros que recebem o ICMS Ecológico e para aqueles que não o recebem. Além disso, foi utilizado o modelo de regressão de dados em painel para área protegida por município para determinar se o ICMS Ecológico contribuiu para a preservação ambiental.

Diante do exposto, observa-se que o ICMS Ecológico é um instrumento importante que pode ser utilizado como fonte de recursos adicionais para municípios que possuam Unidades de Conservação ou tratamento de lixo ou esgoto. Para avaliar os efeitos do ICMS Ecológico nos municípios mineiros, este trabalho teve como objetivo geral avaliar o impacto do ICMS Ecológico na preservação ambiental no estado de Minas Gerais, no período de 1997 a 2007. Especificamente, pretende-se determinar se a transferência de recursos pelo critério ecológico se traduziu efetivamente em aumento das iniciativas locais de gestão ambiental e como o ICMS Ecológico influencia na escolha entre preservação e produção aos municípios. 
Este artigo contém, além dessa introdução, mais três seções. A próxima descreve a metodologia utilizada na análise dos dados. Na terceira, são discutidos os principais resultados encontrados, e a última descreve as conclusões obtidas.

\section{Metodologia}

Na metodologia deste trabalho, foram utilizados cálculos para obter o índice consolidado de produção e de preservação para todos os municípios mineiros e o modelo de dados em painel para verificar qual a relação entre a área protegida e o valor do ICMS Ecológico recebido através do subcritério Unidades de Conservação. A metodologia será apresentada nas seções seguintes.

\subsection{Sistemática do cálculo do índice de participação dos municípios mineiros no ICMS Ecológico}

De acordo com a Lei no 13.803/00 (Lei Robin Hood), o ICMS Ecológico é decomposto em duas partes. Uma diz respeito ao saneamento ambiental $\left(\mathrm{ICMS}^{\mathrm{A}}\right)$ e outra, à Unidade de Conservação (ICMS $)$. A soma das duas partes,

$$
\mathrm{ICMS}^{\mathrm{A}}+\mathrm{ICMS}^{\mathrm{C}}=\mathrm{x} * \mathrm{ICMST}
$$

em que $x$ é a parcela alocada para fins de preservação do meio ambiente (a partir de 1998, x=0,0025) e ICMS ${ }_{T}$ é o total arrecadado do ICMS.

Em seguida, define-se $\mathrm{I}_{\mathrm{j}}$, índice de participação do município $j$ no total do ICMS Ecológico, como sendo:

$$
\mathrm{I}_{\mathrm{j}}=\mathrm{ISA}_{\mathrm{j}}+\mathrm{IC}_{\mathrm{j}}
$$

em que $I S A_{j}$ é o índice de saneamento ambiental do município $j$ e $I C_{j}$ é o índice de conservação do município $j$.

O valor obtido pelo município do ICMS é dado por $\mathrm{I}_{\mathrm{J}}{ }^{*} \mathrm{x}$ * $\mathrm{ICMS}_{\mathrm{T}}$.

O Índice de Saneamento Ambiental pode ser obtido pela seguinte expressão:

$$
\begin{aligned}
& \mathrm{ISA}_{\mathrm{j}}=(1 / \mathrm{N}){ }^{*} \mathrm{ICMS}^{\mathrm{A}} \text {, respeitando a condição } \mathrm{ICMS}^{\mathrm{A}} \leq\left(0,5 * x{ }^{*} \mathrm{ICMS}_{\mathrm{T}}\right) \\
& \mathrm{e}\left(\mathrm{ISA}_{\mathrm{j}}{ }^{*} \mathrm{x}{ }^{*} \mathrm{ICMS} T\right) \leq \mathrm{CP}
\end{aligned}
$$

em que $N$ é o número de municípios que possuem unidades autorizadas pelo Copam para tratamento de esgoto ou para tratamento de lixo e $C P_{j}$ é o custo de implantação da unidade de tratamento de esgoto e/ou lixo do município j.

O Índice de Conservação para o município $j$ é:

$$
\mathrm{IC}_{\mathrm{j}}=\mathrm{FCM}_{\mathrm{j}} / \Sigma_{\mathrm{j}} \mathrm{FCM}_{\mathrm{j}}
$$


em que $F C M_{j}$ é o fator de conservação do município $j$.

A expressão do fator de conservação, por sua vez, pode ser obtida:

$$
\mathrm{FCM}_{\mathrm{j}}=\left(\mathrm{AEuc}_{\mathrm{j}} / \mathrm{Am}_{\mathrm{j}}\right){ }^{*} \mathrm{~F}_{\mathrm{q}}
$$

em que $A E u c_{j}$ é a área equivalente ocupada pelas Unidades de Conservação no município $j ; \mathrm{Am}_{\mathrm{j}}$ é a área total do município $j$ e $F_{q}$ é um fator de qualidade que assume valores de 0,1 a 1 . Esse fator é relativo à qualidade física da área, plano de manejo, infraestrutura, entorno protetor, estrutura de proteção e fiscalização etc. Em Minas Gerais, este fator de qualidade assume valor igual a um.

É importante observar que a área equivalente ocupada pelas Unidades de Conservação no município j pode ser estruturada da seguinte maneira:

$$
\begin{aligned}
& \mathrm{AEuc}_{j}=\mathrm{EE}_{\mathrm{j}}+\mathrm{RB}_{\mathrm{j}}+\mathrm{APAI}_{j}+0,9 \mathrm{PAQ}_{j}+0,9 \mathrm{RPPN}_{j}+0,7 \mathrm{FLO}_{j}+ \\
& 0,5 \mathrm{AI}_{\mathrm{j}}+0,1 \mathrm{APE}_{\mathrm{j}}+0,1 \mathrm{ZVS}_{\mathrm{j}}+0,025 \mathrm{APAII}_{j}
\end{aligned}
$$

em que $E E_{j}$ é a área da estação ecológica ${ }^{9}$ no município $j ; R B_{j}$ é a área da reserva biológica no município j; $Z V S_{j}$ é a zona de vida silvestre no município $j ; P A Q_{j}$ é a área ocupada com parques no município $j ; R P P N_{j}$ é a área ocupada por reserva particular do patrimônio natural no município $j ; F L O_{j}$ é a área ocupada com floresta nacional, estadual ou municipal no município $j ; A I_{j}$ é a área ocupada com reserva indígena no município $j ; A P E_{j}$ é a área de proteção especial no município $j$; $A P A I_{j}$ é a área de proteção ambiental que dispõe de zoneamento ecológico-econômico no município $j$; e, $A P A I I_{j}$ é a área de proteção ambiental que não dispõe de zoneamento ecológico-econômico no município $j$.

\subsection{Compensação}

Muitas áreas protegidas nos municípios são federais ou estaduais e, assim, os governos locais têm geralmente pouca influência na designação destas áreas. Isso afeta a capacidade de o município desenvolver atividades produtivas e gerar renda. Dessa forma, a função de compensação do ICMS Ecológico é importante.

Uma forma de determinar se os municípios estão sendo adequadamente compensados é medir qual a perda econômica gerada pela introdução de áreas de preservação ambiental. Isto só seria possível pela análise das áreas preservadas de cada município e o cálculo do valor adicionado perdido. Esta abordagem é quase inviável pela disponibilidade de dados existentes. Uma abordagem alternativa é usar o valor adicionado por hectare de cada município como indicador do potencial econômico que é perdido quando uma área de terra é "retirada" do processo produtivo para fins de conservação.

9 Ver Anexo B para a definição das áreas de conservação descritas. 
Dessa forma, o cálculo do ICMS perdido pela preservação de uma área, confrontado com o montante recebido pelo município com o ICMS Ecológico, fornecerá um indicador de compensação recebida com o ICMS Ecológico (GRIEG-GRAN, 2000).

O cálculo será realizado para municípios com áreas protegidas e municípios sem estas áreas e serão analisados dois cenários.

1. Uso produtivo de uma área de 1.000 ha, a qual geraria um valor adicionado igual à média comum para o município. A média é calculada pela divisão do valor adicionado total do município pela área total do município.

2. Uma opção de conservação, isto é, a criação de uma área protegida de 1.000 ha.

Nos dois próximos itens, será discutido como é realizado o cálculo para o aumento de 1.000 ha de área produtiva e protegida.

\subsubsection{Aumento de 1.000 ha de área produtiva}

Considere um município $i$, o qual pertence ao estado de Minas Gerais, que recebe num determinado ano $t$, o valor do ICMS (denotado por $I C M S_{i}$ ). O índice consolidado inicial (IC) do município $i$ é:

$$
I C_{i}=\frac{I C M S_{i}}{I C M S_{t}}
$$

em que $I C M S_{t}$ é o total de ICMS destinado aos municípios.

Com um aumento de 1.000 ha na área produtiva, o índice consolidado (IC) passa a ser:

$$
\mathrm{NIC}_{i}=\frac{I C M S_{i}+\Delta I C M S_{i}}{\text { NICMS }_{t}}
$$

em que $\mathrm{NIC}_{i}$ é o novo índice consolidado do município, ICMS $S_{i}$ é o ICMS recebido pelo município $i, \triangle I C M S_{i}$ é a variação no ICMS do município $i$ devido ao aumento de 1.000 ha de área produtiva e NICMS $_{t}$ é o novo total de ICMS destinado aos municípios ${ }^{10}$.

A variação do ICMS $\left(\triangle I C M S_{i}\right)$ pode ser calculada da seguinte forma:

$$
\Delta \mathrm{ICMS} S_{i}=V A_{\text {depois }}-V A_{\text {antes }}
$$

10 O aumento de área produtiva em 1.000 ha na geração de ICMS no estado é muito pequena, assim não é preciso calcular este impacto para cada município. Dessa forma, a mudança principal ocorrerá nos índices de valor adicionado para cada município (equação 13) e considerar-se-á que $\mathrm{NICMS}_{\mathrm{t}}=\mathrm{ICMS}_{\mathrm{t}}$, ou seja, considerar-se-á o "tamanho do bolo" fixo, mudando apenas a "repartição das fatias". 
em que $V A_{\text {depois }}$ é o total que o município recebe de ICMS pelo critério de valor adicionado depois da adição de 1.000 ha de área produtiva e $V A_{\text {antes }}$ é o total de ICMS que o município recebe através do critério valor adicionado sem a adição de 1.000 ha de área produtiva. Tem-se que:

$$
V A_{\text {antes }}=I A_{i} * x * I C M S_{t}
$$

em que $I A_{i}$ é o índice antigo (antes da criação da área produtiva), $x$ é o peso aplicado ao valor adicionado ${ }^{11}$ e ICMS $S_{t}$ é o total de ICMS destinado aos municípios.

O índice antigo $\left(I A_{i}\right)$ pode ser calculado da seguinte forma:

$$
I A_{i}=\frac{V a_{i}}{V a_{t}}
$$

em que $V a_{i}$ é o total de ICMS que o município $i$ recebe através do critério valor adicionado e $V a_{t}$ é o ICMS recebido por todos os municípios mineiros através do critério valor adicionado.

$$
V A_{\text {depois }}=I_{n} * x * I C M S_{t}
$$

em que $I_{n}$ é o novo índice de valor adicionado, o qual pode ser calculado da seguinte forma:

$$
I_{n}=\frac{V a_{i}+1000 * \frac{V a_{i}}{h a_{i}}}{V a_{t}+1000 * \frac{V a_{i}}{h a_{i}}}
$$

em que $V a_{i}$ é o ICMS distribuído ao município i através do critério valor adicionado, $h a_{i}$ é a área total do município e $V a_{t}$ é o ICMS recebido por todos os municípios mineiros através do critério valor adicionado.

A variação doíndice consolidado de produção pode ser calculada subtraindo-se a expressão (7) da (8).

\subsubsection{Aumento de 1.000 ha na área protegida ${ }^{12}$}

Considere que o índice consolidado (IC) do município $i$ num determinado ano é calculado utilizando-se a expressão (7). Com o aumento de 1.000 ha da área protegida, o novo valor do ICMS (denotado por ICMS inovo $_{\text {) }}$ passará a ser:

$$
I C M S_{\text {inovo }}=I C M S_{i}+\Delta\left(I C M S E_{i}\right)
$$

11 Por exemplo, em 1997, o valor de x é de 0,8346. Para os outros anos, os valores estão no anexo A.

12 Este aumento de 1.000 ha na área protegida são para áreas com fator de conservação igual a 1, como por exemplo, as estações ecológicas e as reservas biológicas. 
em que $\triangle\left(I C M S E_{i}\right)$ é a variação do ICMS Ecológico no município $i$ devido ao aumento de 1.000 ha na área protegida.

Para calcular o valor da $\Delta\left(I C M S E_{i}\right)$, utiliza-se a expressão abaixo:

$$
\Delta\left(\mathrm{ICMSE}_{i}\right)=I_{i} * 0,005 * \mathrm{ICMS}_{t}
$$

em que $I_{i}$ é o índice de conservação do município $i$.

Este índice de conservação do município $\left(I_{i}\right)$ pode ser calculado pela expressão (4).

Como a área protegida aumentou em 1.000 ha, o fator de conservação do município $i$ passou a ser:

$$
\mathrm{FCM}_{i}=\left(\frac{1000+A E u c_{i}}{A m_{i}}\right) * F_{q}
$$

O fator de conservação do estado pode ser escrito da seguinte forma:

$$
\sum_{i} F_{C M}=\frac{1000}{A m_{i}} * F_{q}+\sum_{i}\left(\frac{A E u c_{i}}{A m_{i}} * F_{q}\right)
$$

A expressão (17) é válida, pois se pressupõe que só o município $i$ aumenta sua área, ceteris paribus.

$\mathrm{O}$ novo índice consolidado $\left(\mathrm{NIC}_{\mathrm{i}}\right)$ devido ao aumento da área protegida pode ser expresso por:

$$
\mathrm{NIC}_{i}=\frac{I C M S_{i}+\Delta\left(I C M S E_{i}\right)}{I C M S_{t}}
$$

A variação no índice consolidado de preservação é calculada subtraindo-se a expressão (18) da expressão (7).

Depois de calculada a variação do índice consolidado tanto para o aumento da área protegida quanto para o aumento da área produtiva, basta dividir a variação do índice consolidado de produção pela variação do índice consolidado de preservação. Se o valor for maior que um, é melhor para o município $i$ produzir e se for menor que um, é melhor o município preservar.

\subsection{Incentivo}

Um dos objetivos do ICMS Ecológico foi o de incentivar a criação de novas áreas protegidas e melhorar a qualidade das áreas existentes. Para verificar se o ICMS Ecológico levou a uma maior preservação ambiental, o efeito sobre as áreas protegidas em Minas Gerais será mensurado por meio de um modelo de regressão com dados em painel, nos anos de 2000 e 2005.

\subsubsection{Determinantes da área protegida}

Segundo Pindyck e Rubinfeld (2004), dados em painel são um conjunto longitudinal que inclui uma amostra de entidades individuais (famílias, 
municípios, firmas, cidades etc.) ao longo de um período de tempo. É uma combinação de séries temporais com dados de corte transversal.

Neste estudo, o modelo estimado é o seguinte:

$$
\begin{aligned}
& Y_{i t}=\beta_{1}+\beta_{2} \text { PIBPRIMARIO } i t+\beta_{3} \text { VICMSE }_{i t}+\beta_{4} \text { POPULAÇ } \tilde{A} O_{i t}+ \\
& \beta_{5} V A_{i t}+\mu_{i t}
\end{aligned}
$$

em que:

- $Y_{i t}$ é a área protegida no município $i$, no período $t$, (em hectares). Ela refere-se às Unidades de Conservação estaduais, municipais, federais e particulares pertencentes ao município.

- PIBPRIMARIO ${ }_{i t}$ é o PIB do setor primário do município $i$ no período $t$, (em mil reais). Espera-se sinal negativo, pois à medida que vai aumentando o PIB do setor primário, maior tende a ser o desmatamento de áreas, e assim, menor a área protegida. ${ }^{13}$

- VICMSE $E_{i t}$ é o valor do ICMS Ecológico recebido pelo município $i$ no período $t$, através do subcritério Unidades de Conservação, (em reais). Esperase sinal positivo, pois, quanto maior o valor que o município receber de ICMS Ecológico através do subcritério Unidades de Conservação, maior tende a ser a sua preservação.

- POPULAÇÃO ${ }_{i t}$ é o número de habitantes que possui o município i, no período $t$. Espera-se um sinal negativo, pois pressupõe-se que, quando há um aumento populacional, maior será o desmatamento da área para a expansão de áreas de moradia, estradas e serviços.

- $V A_{i t}$ é ICMS recebido pelo município através do critério valor adicionado fiscal (em reais). Espera-se que VA apresente um sinal negativo, pois quanto maior o ICMS do critério valor adicionado que o município receber, maior será a sua atividade econômica e, consequentemente, menor tende a ser a área protegida.

- $\mu_{i t}$ é o erro aleatório.

Neste estudo, será estimado o modelo por efeitos fixos e efeitos aleatórios. Para escolher qual é o melhor modelo, será utilizado o teste de Hausman ${ }^{14}$.

\subsection{Fonte de dados}

Foram utilizados dados anuais, do período de 1997 a 2007, para as seguintes variáveis: área das Unidades de Conservação cadastradas junto à Secretaria de Meio Ambiente e Desenvolvimento Sustentável (Semad); o valor do ICMS distribuído a todos os municípios; o valor do ICMS Ecológico repassado aos

\footnotetext{
13 Ver, por exemplo, Ferreira et al. (2005).

14 Para maiores detalhes, ver Griffiths et al. (1992).
} 
municípios e o ICMS distribuído aos municípios através do critério valor adicionado fiscal foram obtidos junto à Fundação João Pinheiro. Para as variáveis população, Produto Interno Bruto e área dos municípios utilizou-se dados obtidos no site do IBGE (Instituto Brasileiro de Geografia e Estatística). Somente a variável Produto Interno Bruto foi obtida no período de 1999 a 2005 devido à disponibilidade de dados. Todos os valores monetários foram deflacionados pelo Índice Geral de Preços Disponibilidade Interna (IGP-DI), da Fundação Getúlio Vargas.

\section{Resultados e discussão}

\subsection{O ICMS Ecológico como mecanismo de compensação aos municípios mineiros}

Uma das principais justificativas para criação do ICMS Ecológico foi a necessidade de compensação aos municípios que têm áreas em seu território ocupadas por Unidades de Conservação com diversos graus de restrição. Esses municípios não podem utilizar estas áreas para atividades econômicas tradicionais, limitando, dessa forma, o seu desenvolvimento e a sua arrecadação de impostos (VEIGA NETO, 2000).

Desta forma, procurou-se verificar se o ICMS Ecológico vem realmente compensando os municípios que possuem em seu território Unidades de Conservação. Para isto, utilizaram-se mudanças no índice de ICMS Consolidado para um aumento de 1.000 hectares de área protegida e 1.000 hectares para área produtiva para todos os municípios mineiros no período de 1999 a 2005. Os resultados obtidos encontram-se na Tabela 2.

A análise foi feita em relação à importância econômica do município, medida através do Produto Interno Bruto. Para isto, classificaram-se os municípios em: nível de renda baixa, média, média a alta e alta. O valor do PIB para cada uma destas categorias foi, respectivamente, de: até $\mathrm{R} \$ 100.000 .000$; de $\mathrm{R} \$ 100.000 .000,01$ a $R \$ 400.000 .000$; de $R \$ 400.000 .000,01$ a $R \$ 800.000 .000$ e de $R \$ 800.000 .000,01$ em diante $^{15}$ (Tabela 2). A Figura 2 apresenta a porcentagem de municípios mineiros (média de 1999 a 2005) com opção de preservar ou produzir, segundo o nível de renda.

15 Observa-se que, em 2005, existiam 619 municípios com nível de renda baixa, 148 municípios com nível de renda média, 43 municípios com renda média a alta e 43 municípios com renda alta (IBGE, 2007). 
Luciany Lima Fernandes, Alexandre Bragança Coelho,

.533

Elaine Aparecida Fernandes e João Eustáquio de Lima

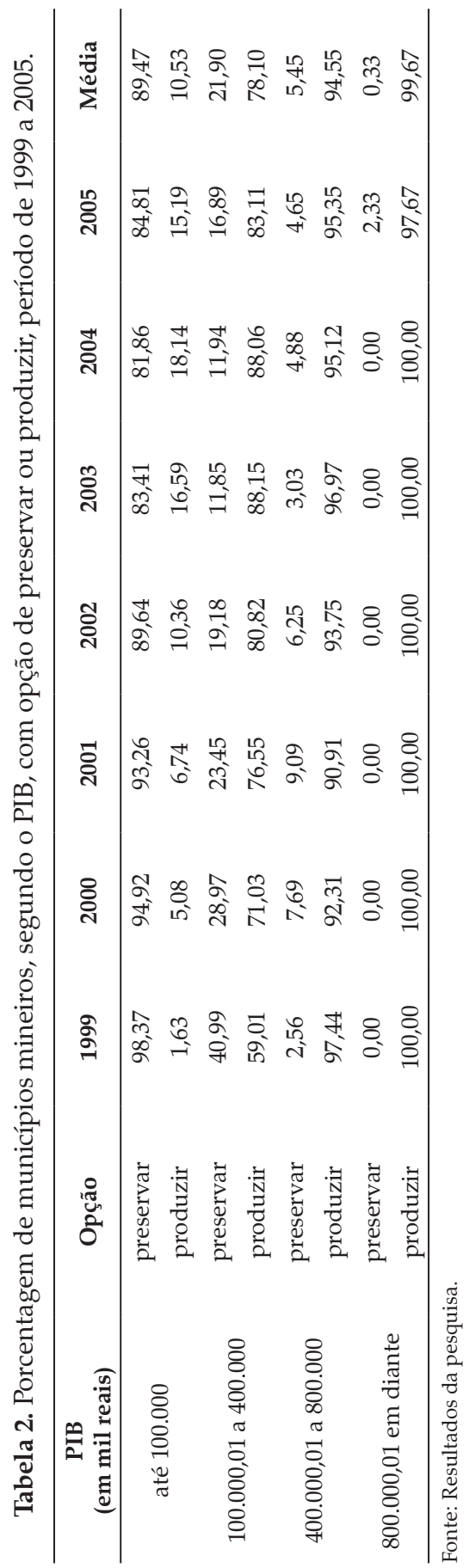

RESR, Piracicaba, SP, vol. 49, no 03, p. 521-544, jul/set 2011 - Impressa em novembro 2011 
Para o grupo de municípios com renda baixa, tem-se, em média, que para 89,47\% dos municípios poderia ser vantajoso preservar uma determinada área. Ao longo do período analisado, observa-se que a opção de preservar é muito atrativa para estes municípios. É importante salientar que, em 1999, 98,37\% destes municípios optariam por preservar e, em 2005, este percentual cai para $84,81 \%$. Essa queda é causada pelo aumento do número de municípios que recebem o ICMS Ecológico e consequente redução do repasse desse recurso por município e também pelo crescimento econômico que aumentou a atratividade da decisão de produzir dos municípios.

Figura 2. Porcentagem de municípios mineiros com opção de preservar ou produzir, segundo o nível de renda (em mil reais), média de 1999 a 2005.

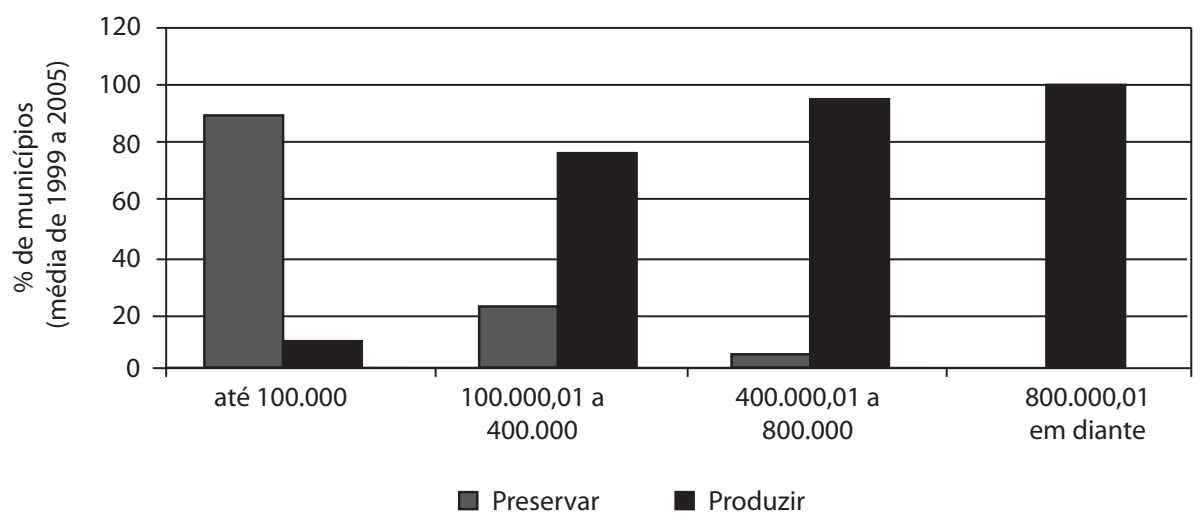

Fonte: Resultados da pesquisa.

Para os municípios com nível de renda média, tem-se que somente $21,90 \%$ seriam compensados com os recursos do ICMS Ecológico, em média, se eles criassem uma área protegida de 1.000 hectares. De 1999 a 2005, observa-se novamente que a atratividade da opção produtiva é cada vez maior.

Para os municípios com nível de renda média a alta, tem-se que 94,55\% dos municípios seriam compensados pela escolha da opção produtiva, em média. Para os municípios com renda alta, os resultados obtidos apresentaram-se de acordo com o esperado. Tem-se, em média, que 99,67\% destes municípios optariam pela atividade produtiva. De 1999 a 2004, 100\% destes municípios optariam por produzir e em 2005, este percentual caiu para 97,67\%.

Verificou-se que, para os municípios menores (pequenos e médios) e os municípios com nível de renda baixa, a opção de proteger uma determinada área é mais vantajosa do que a opção produtiva em termos de recebimento de renda de ICMS. Assim, criar uma área protegida compensaria a maior parte dos 
municípios mineiros em termos de recebimento de renda do ICMS através do critério ambiental, embora se observe que a atratividade da opção de proteger uma determinada área vem diminuindo muito com o passar dos anos, devido à porcentagem distribuída aos municípios ser fixa ao longo do tempo.

\subsection{O ICMS Ecológico como mecanismo de incentivo aos municípios mineiros}

O ICMS Ecológico foi criado também com o objetivo de incentivar os municípios a preservarem suas Unidades de Conservação e, além disso, incentivá-los a criarem novas áreas protegidas. Para efeito da legislação, essas áreas têm que ser cadastradas junto à Secretaria de Meio Ambiente e Desenvolvimento Sustentável (Semad), após a avaliação técnica do Instituto Estadual de Florestas (IEF), para receberem os recursos do ICMS Ecológico. Na Figura 3, tem-se o total de área protegida (em hectares) de todas as Unidades de Conservação cadastradas em Minas Gerais, no período de 1997 a 2007.

Observa-se que a área protegida vem crescendo bastante desde 1997, com aumento de aproximadamente $400 \%$ até 2006. Em 1997, a área protegida do estado era de cerca de 1,14 milhões de hectares e, em 2006, este valor subiu para 4,93 milhões de hectares. De 2006 para 2007, houve queda no total da área protegida, que, segundo informações recebidas da Fundação João Pinheiro, se deve a falhas no recadastramento destas Unidades de Conservação.

Figura 3. Total da área protegida (em hectares) no estado de Minas Gerais, anos 1997 a 2007.

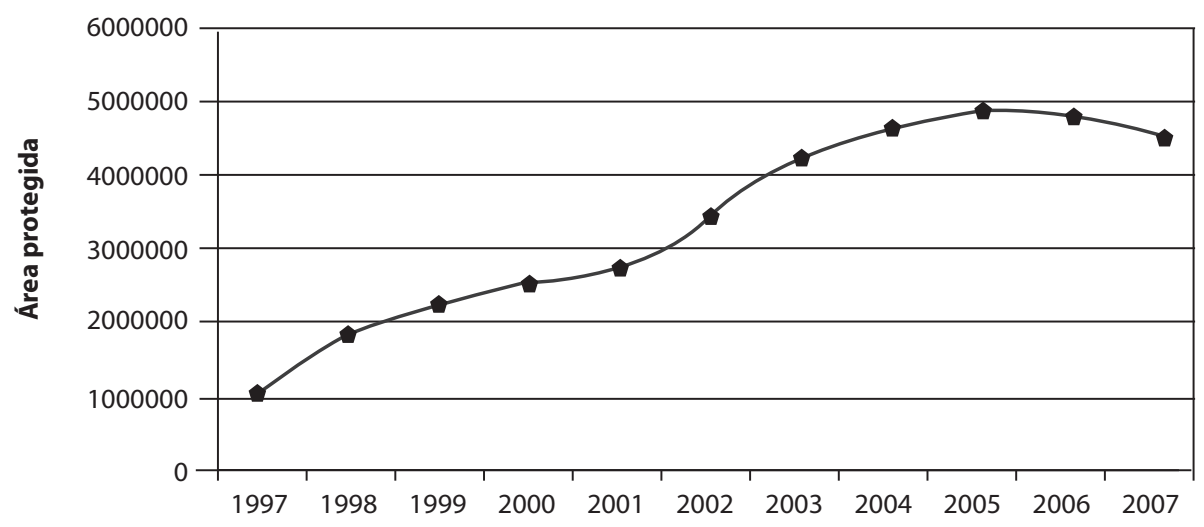

Anos

Fonte: Fundação João Pinheiro. 
Euclydes e Magalhães (2006) verificaram que, até dezembro de 1995, havia 109 Unidades de Conservação e, em 2005, este valor passou para 440. As áreas de proteção ambiental municipais foram as que tiveram maior aumento, passando de 6 para 155 somente neste período. O aumento destas áreas fez com que o total da área protegida no estado crescesse mais de $60 \%$ e elas deixaram de representar apenas $0,7 \%$ do total da área protegida para representarem $40 \%$ em menos de 10 anos (Quadro 1). Observa-se que, com o ICMS Ecológico, muitos municípios acharam interessante a idéia de criarem Unidades de Conservação dentro de seu território, pois, ao preservarem estas áreas, eles receberiam compensação financeira.

Quadro 1. Criação de Unidades de Conservação, antes e depois do ICMS Ecológico.

\begin{tabular}{|c|c|c|c|}
\hline \multicolumn{4}{|c|}{ Criação de Unidades de Conservação } \\
\hline Proteção Integral & Até dez/1995 & Até dez/2005 & Total \\
\hline EEE & 7 & 2 & 9 \\
\hline EEF & 1 & 0 & 1 \\
\hline EEM & 0 & 1 & 1 \\
\hline RBE & 1 & 1 & 2 \\
\hline RBF & 1 & 0 & 1 \\
\hline RBM & 7 & 9 & 16 \\
\hline PAQE & 8 & 15 & 23 \\
\hline PAQF & 5 & 2 & 7 \\
\hline PAQM & 22 & 20 & 42 \\
\hline Zona de Vida Silvestre & 0 & 1 & 1 \\
\hline Total & 52 & 51 & 103 \\
\hline Uso Sustentável & Até dez/1995 & Até dez/2005 & Total \\
\hline Apae & 6 & 7 & 13 \\
\hline Apaf & 4 & 0 & 4 \\
\hline Apam & 6 & 149 & 155 \\
\hline Floe & 0 & 2 & 2 \\
\hline Flom & 0 & 1 & 1 \\
\hline Flona & 1 & 2 & 3 \\
\hline RPPNE & 0 & 70 & 70 \\
\hline RPPNF & 16 & 46 & 62 \\
\hline Redes & 0 & 1 & 1 \\
\hline Total & 33 & 278 & 311 \\
\hline Áreas protegidas & Até dez/1995 & Até dez/2005 & Total \\
\hline APEE & 19 & 1 & 20 \\
\hline Apem & 1 & 1 & 2 \\
\hline Total & 20 & 2 & 22 \\
\hline Áreas Indígenas & 4 & 0 & 4 \\
\hline
\end{tabular}

Nota: O significado de cada uma das siglas encontra-se no anexo B, e as letras M, E e F no final de cada sigla, significam municipal, estadual e federal.

Fonte: Euclydes e Magalhães (2006). 
Segundo Veiga Neto (2000), um ponto interessante neste crescimento de municípios habilitados foi o fato de que o crescimento aconteceu devido não só à criação real de novas Unidades de Conservação, mas também em função da procura do órgão ambiental pelos municípios para cadastramento de áreas preexistentes, mas não regulamentadas, trazendo já uma importante consequência do ICMS Ecológico: a preocupação com a regulamentação das áreas de conservação.

\subsection{Relação entre a área protegida e o valor do ICMS Ecológico (subcritério Unidades de Conservação)}

Para saber qual a relação entre a variável dependente área protegida ${ }^{16}$ e as variáveis explicativas (valor adicionado, PIB-primário, população e valor do ICMS Ecológico recebido através do subcritério Unidades de Conservação), foi estimada a equação (19). Estimou-se o modelo com efeitos fixos e com efeitos aleatórios. As estatísticas descritivas para as variáveis do modelo estão na Tabela 3.

Tabela 3. Estatísticas descritivas para as variáveis do modelo de dados em painel.

\begin{tabular}{cccccc}
\hline Variável & $\begin{array}{c}\text { Área } \\
\text { protegida }\end{array}$ & PIB-primário & População & VA & VICMSE \\
\hline Média & $4.356,09$ & $19.089,92$ & $21.529,75$ & 3.197 .082 & $19.579,67$ \\
Mediana & 0,00 & $9.840,75$ & 7.523 & $351.206,8$ & 0,00 \\
Máximo & $262.992,90$ & $397.407,5$ & 2.375 .329 & $3,20 \times 10^{8}$ & 1.211 .766 \\
Mínimo & 0,00 & 0,00 & 825,00 & $5.063,29$ & $-262.809,4$ \\
Desvio Padrão & $15.204,11$ & $29.572,11$ & $88.700,38$ & 17.296 .739 & $71.039,25$ \\
\hline
\end{tabular}

Fonte: Resultados da pesquisa.

O primeiro teste utilizado para a escolha do modelo foi o teste de Chow, que possibilita escolher entre o modelo sem efeitos e o modelo de efeitos fixos (Tabela 4). A estatística calculada rejeitou a hipótese nula de que todos os parâmetros de interceptos sejam iguais, ou seja, o modelo por dados agrupados não é o melhor, sendo aceitas as estimativas obtidas com o modelo irrestrito ou de efeitos fixos.

A próxima etapa consistiu em comparar o modelo de efeitos aleatórios com um modelo com ausência de efeitos por meio do teste LM de Breusch e Pagan. $\mathrm{O}$ valor tabelado a $1 \%$ de confiança para a estatística de $\mathrm{x}^{2}$ com 1 grau

16 Inicialmente, a proposta do trabalho era trabalhar com a área desmatada de todos os municípios de Minas Gerais, ao invés da área protegida. Como não houve disponibilidade de dados referentes à área desmatada, optou-se por utilizar a área protegida. 
de liberdade é de 6,63, menor, portanto, que o valor calculado da estatística LM $(429,88)$. Rejeita-se, assim, a hipótese nula do modelo com ausência de efeitos, o que resulta na preferência pelo modelo de efeitos aleatórios.

A última etapa foi utilizar o teste proposto por Hausman, para verificar qual efeito é o mais indicado, efeitos fixos ou aleatórios. $\mathrm{O}$ valor calculado da estatística foi de 13,04, maior que o valor do $\mathrm{x}^{2}$ tabelado com 4 graus de liberdade a $5 \%$ de probabilidade $(9,49)$. Portanto, rejeita-se a hipótese nula de que o modelo de efeitos aleatórios é melhor. Optou-se, então, pelo modelo de efeitos fixos. Os resultados encontrados para o modelo de efeitos fixos podem ser observados na Tabela 4.

Tabela 4. Função área protegida dos municípios mineiros estimada com presença de efeitos fixos, ano de 2000 e 2005.

\begin{tabular}{lccc}
\hline Variáveis & Coeficiente & Erro padrão & Valor-p \\
\hline Constante & $3971,11^{* * *}$ & 13,2264 & 0,0000 \\
VICMSE & $0,0414^{* * *}$ & 0,0007 & 0,0000 \\
Pibprimario & $0,0023^{* * *}$ & $7,32 \times 10^{-5}$ & 0,0000 \\
VA & $-1,30 \times 10^{-5 * * *}$ & $7,27 \times 10^{-7}$ & 0,0000 \\
População & $-0,0199^{* * *}$ & 0,0007 & 0,0000 \\
\hline$R^{2}$ & 0,9981 & & \\
Estatística F & $509,87^{* * *}$ & & 0,0000 \\
Hausman & $13,04^{* *}$ & & 0,0111 \\
LM & $429,88^{* * *}$ & & 0,0000 \\
BG & $848^{* * *}$ & & \\
White & $24,14^{\mathrm{NS}}$ & & \\
Chow & $5,89^{* * *}$ & & \\
\hline
\end{tabular}

*** significativo a $1 \%$; ** significativo a $5 \%$; * significativo a $10 \%$; NS não significativo Hausman: $\chi_{(4 ; 5 \%)}^{2}=9,49$

LM: $\chi_{(1 ; 1 \%)}^{2}=6,63$

BG: $\mathrm{N}=853, \mathrm{p}=5, \chi_{(5 ; 1 \%)}^{2}=15,09$

White: $\mathrm{N}=1706, \mathrm{p}=14, \chi_{(14 ; 1 \%)}^{2}=29,14$

Chow: $\mathrm{F}_{(852 ; 849 ; 1 \%)}=1,00$.

Fonte: Resultados da pesquisa.

Com relação à presença de autocorrelação, utilizou-se o teste de Breusch-Godfrey, em que a hipótese nula é que o modelo proposto na Tabela 4 não apresente autocorrelação, contra a hipótese alternativa que o modelo tenha autocorrelação. A estatística do teste foi de 848 , sendo maior que o valor $\mathrm{x}^{2}$ tabelado com 5 graus de liberdade a $1 \%$ de probabilidade; logo, rejeita-se a hipótese nula e o modelo apresenta problemas de autocorrelação. Entretanto, preferiu-se não corrigi-lo, pois o mesmo possui somente duas observações temporais, o que pode ser entendido como uma limitação deste estudo. 
Para verificar se o modelo de efeitos fixos tem problemas de heterocedasticidade, utilizou-se o teste de White. O valor calculado foi de 24,14 e o valor do $\mathrm{x}^{2}$ tabelado com 14 graus de liberdade a $1 \%$ de probabilidade foi de 29,14 . Como o valor calculado foi menor que o valor crítico tabelado, não se rejeita a hipótese nula que o modelo é homocedástico. Portanto, o modelo de efeitos fixos não apresenta problemas de heterocedasticidade.

Pode-se notar que todas as variáveis foram estatisticamente significativas. O valor do $\mathrm{R}^{2}$ foi bastante alto, mostrando que $99,81 \%$ da variação na área protegida é explicada pelas variáveis VA, POPULAÇÃO, PIBPRIMARIO e VICMSE. A variável PIBPRIMARIO apresentou sinal positivo diferente do esperado. Dado um aumento de R\$ 1.000.000,00 no PIB primário, a área protegida aumenta em 2,3 hectares.

A variável ICMS distribuída aos municípios através do critério valor adicionado (VA) apresentou sinal negativo, conforme o esperado. Seu efeito, entretanto, foi bastante reduzido. Dado um aumento de R \$1.000,00 no ICMS recebido através do critério valor adicionado, a área protegida diminui em apenas 0,013 hectares.

A variável POPULAÇÃO apresentou sinal negativo em relação à área protegida, ou seja, dado um aumento de 1.000 habitantes, a área protegida diminui em 19,9 hectares. Isso era esperado, pois quando há um aumento populacional, espera-se também um maior desmatamento para a expansão de áreas de moradia, estradas e serviços.

Confirmando a expectativa inicial, o valor do ICMS Ecológico através do subcritério Unidades de Conservação apresentou sinal positivo em relação à área protegida. Um aumento de R $\$ 1.000,00$ no valor que o município recebe de ICMS Ecológico através do subcritério Unidades de Conservação faz com que a área protegida aumente em 41,4 hectares. Isto mostra a importância do ICMS Ecológico para a preservação e conservação do meio ambiente, funcionando como forte incentivo para a criação de novas áreas protegidas (Unidades de Conservação).

\section{Conclusões}

O ICMS Ecológico foi um instrumento inovador criado no estado do Paraná em 1991. Em Minas Gerais, ele foi criado em 1995 com o objetivo de compensar e incentivar os municípios que possuíam Unidades de Conservação ou aqueles que possuem sistemas de disposição e tratamento de lixos e esgotos sanitários, destinando a eles $1 \%$ dos recursos do ICMS.

Assim, diante dos resultados obtidos, pode-se concluir que o ICMS Ecológico é um importante mecanismo de compensação e incentivo aos municípios mineiros. Com relação ao mecanismo de compensação, verificou-se que, para os municípios com nível de renda baixa, a opção de proteger uma determinada área é mais vantajosa do que a opção produtiva em termos de recebimento de 
renda de ICMS. Assim, criar uma área protegida compensaria a maior parte dos municípios mineiros em termos de recebimento de renda do ICMS através do critério ambiental, embora se observe que a atratividade da opção de proteger uma determinada área vem diminuindo muito com o passar dos anos, devido à porcentagem distribuída aos municípios ser fixa ao longo do tempo.

Com relação ao mecanismo de incentivo do ICMS Ecológico através do subcritério Unidades de Conservação, observou-se que, no período de 1997 a 2006, a área protegida teve aumento de $400 \%$ em relação a 1997. Além disso, o número de municípios que receberam o ICMS Ecológico cresceu consideravelmente nesse período, mostrando a importância do critério ecológico para eles.

Verificou-se também que quanto maior o valor do ICMS Ecológico que o município recebe através do subcritério Unidades de Conservação, maior tende a ser a sua área protegida. Isto mostra a importância que o ICMS Ecológico possui para a conservação e preservação do meio ambiente. Assim, pode-se concluir que o ICMS Ecológico vem incentivando os municípios mineiros a criarem Unidades de Conservação.

Recomenda-se que haja uma reformulação nos critérios da Lei Robin Hood para que se aumente o percentual de ICMS Ecológico destinado aos municípios mineiros, de forma que não seja comprometida a eficácia de seu estímulo para os municípios se engajarem em ações de preservação. Além disso, é necessário que se coloque em prática o fator que analisa a qualidade das Unidades de Conservação, para que o aumento nas estatísticas da área total dessas Unidades se traduza efetivamente em ganho ambiental para o estado de Minas Gerais.

\section{Referências Bibliográficas}

AMAPÁ. Lei n 322, de 23 de dezembro de 1996. Aprova o ICMS Ecológico. Diário Oficial do Estado, Macapá, 1996.

BOTELHO, D.O., SILVA, S.S., AMÂNCIO, R., PEREIRA, J.R., AMÂNCIO, C.O.G. ICMS-Ecológico como instrumento de política ambiental em Minas Gerais. In: Congresso da Sociedade Brasileira de Economia, Administração e Sociologia Rural, 45. 2007, Londrina. Anais... Londrina. UEL, 2007. 1 CD-ROM.

EUCLYDES, A.C.P., MAGALHÃES, S.R.A. Considerações sobre a categoria de manejo "Área de Proteção Ambiental (APA)" e o ICMS Ecológico em Minas Gerais. In: XII Seminário sobre a economia mineira. Disponível em: http://www. cedeplar.ufmg.br/seminarios/seminario_diamantina/2006/D06A105.pdf. Acesso em set. 2007.

FERNANDES, L.L. ICMS Ecológico como mecanismo de distribuição, compensação e incentivo no Estado de Minas Gerais. Viçosa, MG. DER-UFV, 2008. 132f. Dissertação (Mestrado em Economia Aplicada). 
FERREIRA, L.V., VENTICINQUE, E., ALMEIDA, S. O desmatamento na Amazônia e a importância das áreas protegidas. Estudos avançados 19, 2005. Disponível em: http://www.scielo.br/pdf/ea/v19n53/24086.pdf. Acesso em out. 2009.

FJP - FUNDAÇÃO JOÃO PINHEIRO. Disponível em: http://www.fjp.gov.br. Acesso em 11 de ago. 2007.

GRIEG-GRAN, M. Fiscal incentives for biodiversity conservation: The ICMS Ecológico in Brazil. Discussion Paper 00-01 International Institute for Environment and Development, London, UK. 2000.

GRIFFITHS, W.E.; HILL, R.C.; JUDGE, G.G. Learning and Practicing Econometrics. New York: John Wiley \& Song, Inc, 1992, p. 866.

IBGE - INSTITUTO BRASILEIRO DE GEOGRAFIA E ESTATÍSTICA. Disponível em: http://www.ibge.gov.br. Acesso em set. 2007.

LOUREIRO, W. Contribuição do ICMS Ecológico à conservação da biodiversidade no Estado do Paraná. Curitiba, PR, UFPR. 2002. 189f.; Dissertação (Doutorado em Ciências Florestais).

MATO GROSSO DO SUL. Lei n 2193, de 18 de dezembro de 2000. Dispõe sobre o ICMS Ecológico e dá outras providências. Diário Oficial do Mato Grosso do Sul, Campo Grande, 2000.

MATO GROSSO. Lei Complementar n 73, de 07 de dezembro de 2000. Dispõe sobre os critérios de distribuição da parcela de receita do ICMS e dá outras providências. Diário Oficial do Mato Grosso, Cuiabá, 2000.

MINAS GERAIS. Lei $n^{\circ} 12.040$, de 28 de dezembro de 1995. Dispõe sobre a distribuição da parcela de receita do produto da arrecadação do ICMS pertencente aos municípios, de que trata o inciso II do parágrafo único do artigo 158 da Constituição Federal, e dá outras providências. Diário Oficial do Estado de Minas Gerais, Belo Horizonte, 1995.

. Lei $\mathrm{n}^{\circ} 13.803$, de 27 de dezembro de 2000. Dispõe sobre a distribuição da parcela de receita do produto da arrecadação do ICMS pertencente aos municípios, de que trata o inciso II do parágrafo único do artigo 158 da Constituição Federal, e dá outras providências. Diário Oficial do Estado de Minas Gerais, Belo Horizonte, 2000.

NUNES, L.H.C. ICMS Ecológico: revisão crítica dos critérios de distribuição do produto da arrecadação dos impostos pertencentes aos municípios. Belo Horizonte, MG Fundação João Pinheiro. 2003. 143f.; Dissertação (Mestrado em Administração Pública).

PARANÁ. Lei Complementar n 9491, de 21 de dezembro de 1990. Estabelece critérios para fixação dos índices de participação dos municípios no produto de arrecadação do ICMS. Diário Oficial do Estado do Paraná, Curitiba, 1991. 
PERNAMBUCO. Lei $n^{\circ} 11899$. Redefine os critérios de distribuição da parte do ICMS que cabe aos Municípios e dá outras providências. Diário Oficial do Estado de Pernambuco, Recife, 2000.

PINDYCK, R.S., RUBINFELD, D.L. Econometria Modelos \& Previsões. Rio de

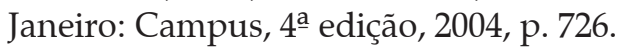

RIO DE JANEIRO. Lei n ${ }^{\circ} 5100$, de 4 de outubro de 2007. Altera a Lei n ${ }^{\circ} .664$, de 27 de dezembro de 1996, que trata da repartição aos municípios da parcela de $25 \%$ do produto da arrecadação do ICMS, incluindo o critério de conservação ambiental, e dá outras providências. Diário Oficial do Estado do Rio de Janeiro, Rio de Janeiro, 2007.

RIO GRANDE DO SUL. Lei ${ }^{\circ} 11038$ de 17 de novembro de 1997. Dispõe sobre a parcela do produto de arrecadação do Imposto Relativo à Circulação de Mercadorias e Serviços (ICMS) pertencentes aos municípios. Diário Oficial do Estado do Rio Grande do Sul, Porto Alegre, 1997.

RONDÔNIA. Lei Complementar n 147 de 15 de janeiro de 1996. Disciplina a distribuição das parcelas do Imposto sobre Operações Relativas à Circulação de Mercadorias (ICMS), destinadas aos municípios. Diário Oficial do Estado de Rondônia, Porto Velho, 1996.

SÃO PAULO. Lei n ${ }^{\circ} 8510$, de 29 de dezembro de 1993. Altera a Lei 3201, de 23 de dezembro de 1981, que dispõe sobre a parcela, pertencente aos municípios, do produto de arrecadação do ICMS. Diário Oficial do Estado de São Paulo, São Paulo, 1993.

TOCANTINS. Lei n ${ }^{\circ}$ 1323/02. Dispõe sobre o ICMS ecológico. Diário Oficial do Tocantins, Palmas, 2002.

VEIGA NETO, F.C. Análise de incentivos econômicos nas políticas públicas para o meio ambiente - O caso do ICMS Ecológico em Minas Gerais. Rio de Janeiro, R.J. Universidade Federal Rural do Rio de Janeiro, 2000. 161f. Dissertação (Mestrado em Desenvolvimento, Agricultura e Sociedade). 
Luciany Lima Fernandes, Alexandre Bragança Coelho,

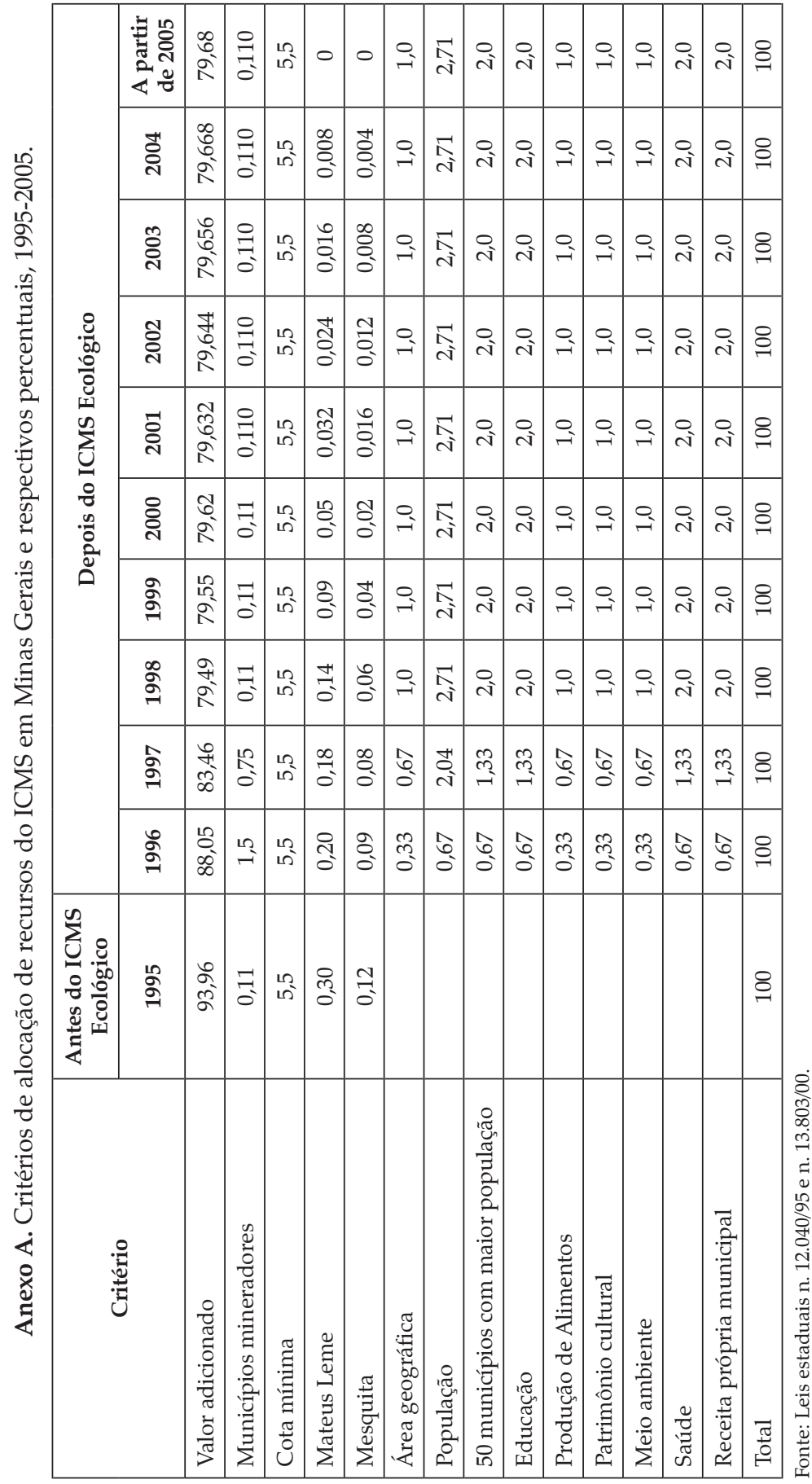




\section{Anexo B \\ Definição das áreas de conservação presentes no estudo}

a) Estação Ecológica (EE): é uma unidade de conservação que tem como objetivo a preservação da natureza e a realização de pesquisas científicas. É proibida a visitação pública, exceto com objetivo educacional e a pesquisa científica.

b) Reserva Biológica (RB): tem como objetivo a preservação integral da biota e dos demais recursos naturais existentes em seus limites, sem interferência humana direta.

c) Zona de vida silvestre (ZVS): tem o objetivo de proteger ambientes naturais onde se asseguram condições para a existência ou reprodução de espécies ou comunidades da flora local e da fauna residente ou migratória.

d) Área ocupada com parques (PAQ): são áreas geográficas extensas e delimitadas, dotadas de atributos naturais excepcionais, Destinam-se a fins científicos, culturais, educacionais e recreativos, condicionada à visitação pública, mas com restrições específicas. São de domínio público.

e) Reserva Particular do Patrimônio Natural (RPPN): é uma área privada, gravada com perpetuidade, com o objetivo de conservar a diversidade biológica no Brasil e promover a educação ambiental, para que as futuras gerações possam desfrutar do privilégio de uma natureza conservada.

f) Área ocupada com floresta nacional, estadual ou municipal (FLO): são áreas de domínio público, federal, estadual ou municipal, criadas com o objetivo de aliar conservação e manejo de áreas naturais e plantadas, visando pesquisar e disseminar espécies florestais produtivas.

g) Área ocupada com reserva indígena (AI): não são consideradas unidades de conservação; foram incluídas nos cálculos para o "ICMS Ecológico" porque implicam em um nível de restrição de uso do solo que justifica sua inclusão.

h) Área de Proteção Especial (APE): é uma área de conservação que visa à proteção de mananciais, patrimônio paisagístico e arqueológico.

i) Área de Proteção Ambiental (Apai): é uma área em geral extensa, com um certo grau de ocupação humana. Tem como objetivos básicos proteger a diversidade biológica, disciplinar o processo de ocupação e assegurar a sustentabilidade do uso dos recursos naturais. Neste estudo, ficou sendo definida Apai como área de proteção ambiental que dispõe de zoneamento ecológico-econômico e Apaii, que não dispõe de zoneamento ecológico-econômico. 